\title{
Numerical Simulation Research on Radial Force of Centrifugal Pump with Guide Vanes
}

\author{
Dongrong Meng $\mathbb{D}^{1},{ }^{1}$ Ting Jiang, ${ }^{2}$ Hongling Deng, ${ }^{3}$ and Gaoyang Hou $\mathbb{D}^{4}$ \\ ${ }^{1}$ School of Mechanical Engineering, Xijing University, Xi'an 710123, China \\ ${ }^{2}$ Innovation Institute of Shaanxi Aerospace Power High Tech Co., Ltd, Xi'an 710077, China \\ ${ }^{3}$ Department of Mechanical and Industrial Engineering, New Jersey Institute of Technology, Newark, NJ 07102, USA \\ ${ }^{4}$ Department of Power and Electrical Engineering, Northwest A\&F University, Yangling, Shaanxi 712100, China \\ Correspondence should be addressed to Gaoyang Hou; gyhou415@nwafu.edu.cn
}

Received 30 October 2020; Revised 16 December 2020; Accepted 1 January 2021; Published 29 January 2021

Academic Editor: Yong Zhu

Copyright ( 2021 Dongrong Meng et al. This is an open access article distributed under the Creative Commons Attribution License, which permits unrestricted use, distribution, and reproduction in any medium, provided the original work is properly cited.

\begin{abstract}
To reveal the internal unsteady flow state of the guide vane centrifugal pump, in this paper, the standard SST k- $\omega$ turbulent flow model is used for unsteady numerical simulation of the centrifugal pump. The characteristics of the flow field inside the centrifugal pump are analyzed, the resultant force and vector distribution of the radial force of the guide vane and impeller of the centrifugal pump under different flow rates are obtained, which were verified by experiments. The results show that the main reason of radial force of the impeller is the pressure asymmetry in each flow passage. The radial force will show periodic fluctuations due to the rotor-stator interference between the impeller and the guide vanes under different flow rates. The radial force on the impeller decreases gradually with the increase of the flow, the distribution is hexagonal or hexagonal shape, and the number of impeller blades is the same. The results can provide reference for the design of impeller and guide vane of centrifugal pump.
\end{abstract}

\section{Introduction}

Pump is a machine with a wide range of applications. With the development of national economy and science and technology, pumps are widely used in various fields. During the operation of a centrifugal pump, there is a complex three-dimensional unsteady flow inside the pump, often accompanied by flow separation, cavitation, vibration, and other phenomena that affect the performance of the unit $[1,2]$. Hydraulic excitation has the greatest impact on the performance of the unit, and the static and dynamic interference between the impeller and the diaphragm is the main reason for the radial force generated inside the centrifugal pump [3], which has become a hot spot in the research of pump stability.

In recent years, domestic and foreign scholars have carried out a lot of research work on guide vane centrifugal pumps by using experimental [4] and numerical simulation methods $[5,6]$. Intelligent diagnosis of pump mechanical faults through artificial neural networks has also become an academic hot spot in recent years [7-9]. Yang et al. used numerical simulation methods to study centrifugal pumps with different forms of diaphragms [10]. They found that the inlet and outlet pressure and pulsation amplitude of stepped diaphragm centrifugal pumps were weakened, and the highfrequency pulsation components acted on the worm were reduced, with the decrease in radial force value and pulsation amplitude on the shell. Stel et al. [11] and Segala et al. [12] took a two-stage centrifugal pump as the research object and found that the flow in the guide vane is similar at different speeds. Guo et al. studied the resonance characteristics of the guide vane centrifugal pump through experiments [13] and pointed out when the dynamic and static interference between the impeller and the guide vane is weak, the pressure pulsation is distributed in the circumferential direction of the impeller, resulting in radial force. Oliver et al. [14, 15], Xiaodong [16], and Sun Qingchong [17] et al. used numerical analysis and test methods to study the unsteady flow 
inside the guide vane centrifugal pump, mainly to illustrate the guide vane-type impeller-guide vane rotor-stator interference mechanism in the centrifugal pump. Wangchang [18] discussed the generation mechanism of pressure pulsation based on experiments on multistage pumps, pointing out that the blade frequency pressure pulsation depends on the hydraulic design of the pump. Chalghoum et al. proved that the pressure fluctuation is periodic due to the relative position of the impeller blade to volute tongue [19]. Yue Hao et al. found the unsymmetrical tip clearance makes the pump cavitation performance worse and influences the magnitude of radial force [20]. The shaft frequency pressure pulsation depends on factors of dynamic and static disturbances $[21,22]$. Krause et al. used a numerical simulation method for a double volute pump with a diaphragm to analyze the pressure pulsation characteristics in the centrifugal pump and the radial force characteristics of the impeller [23].

With the increasing requirements for the operation stability of centrifugal pumps in industrial and agricultural production, the research on the internal pressure pulsation and radial force of centrifugal pumps has always been the focus and hot issue of the current research [24-28]. In this paper, ANSYS CFX numerical simulation software is used to simulate a certain type of guide vane of centrifugal pump with inconstant value, and it is verified by experiment. The focus is on the hydraulic performance of the impeller and guide vane, the internal unsteady flow field, and the radial force acting on the impeller.

\section{Methods and Experiments}

2.1. Calculation Objects and Meshing. The main parameters of the model pump are as follows: speed $n=1450 \mathrm{r} / \mathrm{min}$, design flow $Q_{\mathrm{d}}=40 \mathrm{~m}^{3} / \mathrm{h}$, and design head $H_{\mathrm{d}}=60 \mathrm{~m}$. In order to verify the accuracy of the numerical simulation, two monitoring points were set in the guide vane channel and two monitoring points were set near the volute separation tongue, a total of four monitoring points were selected. P1 and $\mathrm{P} 2$ are located near the middle section of the guide vane channel and the exit of the guide vane; P3 and P4 are located near the volute separation tongue and the volute exit, as shown in Figure 1. The basic parameters of the guide vane centrifugal pump are shown in Table 1.

The calculation domain includes five parts: inlet section, impeller, guide vane, volute, and outlet section. The model is meshed with ICEM software. The meshes are locally refined around the blades, volutes, and walls. The grid numbers of the inlet section, impeller, guide vane, volute, and outlet section are 210362, 195321, 902035, 776637, and 1278223, respectively. The calculation domain and grid division results are shown in Figure 2. The turbulence model adopts the SST k- $\omega$ model, and the steady-state calculation boundary conditions adopt the total pressure inlet and the mass flow outlet. The wall has no slip boundary conditions. Transient calculation is based on steady-state calculation as the initial condition. Each time the impeller rotates $3^{\circ}$ is a time step, the time step is 0.000172414 . 10 cycles are running with 120 iterative steps for each run. As a result, the last cycle is chosen for numerical analysis.
2.2. Numerical Simulation and Experimental Verification. The guide vane centrifugal pump impeller, guide vanes, and volute adopt plexiglass $3 \mathrm{D}$ printing technology. The guide vanes are evenly fixed on the bracket. The corresponding characteristic curves are obtained from the test results. The torque measurement used the JN338 speed torque sensor (Beijing Sanjing), and the measurement error is $\pm 0.2 \%$; the flow measurement used the AE215 electromagnetic flowmeter, and its measurement error is $\pm 0.5 \%$; the import and export pressure measurement used the EJA510A pressure sensor, and the measurement error is $\pm 0.075 \%$.

Figure 3 shows the comparison between the numerical simulation and experimental results of the external characteristics of the guide vane centrifugal pump. It can be seen from the figure that the highest efficiency of the model pump is not at the design operating point $\left(Q_{\mathrm{d}}=40 \mathrm{~m}^{3} / \mathrm{h}\right)$, but at the $Q=38 \mathrm{~m}^{3} / \mathrm{h}$ operating point. This phenomenon may be due to the small throat area of the guide vane, leading to the highest efficiency deviation to small flow. The external characteristic curve of the numerical simulation is in good agreement with the test curve, especially around $Q=40 \mathrm{~m}^{3} /$ h. The error of the head and efficiency of the numerical simulation with test value are all within $5 \%$; when the flow is too large $\left(Q\right.$ is greater than $56 \mathrm{~m}^{3} / \mathrm{h}$ ), the error between numerical simulation and test value is slightly larger, which is $7.39 \%$. The steady calculation method can accurately predict the external characteristics of the pump in a larger flow range. The numerical simulation has certain reliability, so it can be used to further reflect $Q=25 \mathrm{~m}^{3} / \mathrm{h}$ to $Q=47 \mathrm{~m}^{3} / \mathrm{h}$ flow field characteristics in the pump under nondesign conditions and provide guidance for analyzing the influence of the pump internal flow field on the radial force.

Figure 4 shows the comparison between the numerical simulation and the experiment of the time-domain diagram and frequency-domain diagram of the pressure pulsation at monitoring points $\mathrm{P} 3$ and $\mathrm{P} 4$ under $1.0 \mathrm{Q} / \mathrm{Q}_{\mathrm{d}}$ flow conditions. The pressure fluctuation coefficient is used to characterize the pressure fluctuation as follows:

$$
C_{p}=\frac{p_{\text {trn }}-p_{\text {ave }}}{0.5 \rho u_{2}},
$$

where $P_{\mathrm{tm}}$ is the instantaneous value of pressure $(\mathrm{Pa})$ and $P_{\text {ave }}$ is the average value of pressure $(\mathrm{Pa})$.

It can be seen from the figure that the distribution trend of the time-domain curve of the numerical simulation pressure pulsation is similar to that of the test and the simulated values of the pressure pulsation coefficients at the monitoring points $P 3$ and $P 4$ are slightly higher than the test values. Under the influence of dynamic and static interference, the pressure pulsation coefficient fluctuates periodically. The time-domain distribution of pressure pulsation at the monitoring point $P 3$ is in good agreement with the test value, while the time-domain distribution at the monitoring point $P 4$ is in poor agreement with the test value. The reason may be fluid in A turbulent flow is formed near the compartment, part of the fluid flows to the outlet of the volute, and part of the fluid flows from the smaller cross-flow section of the volute to the outlet flow. As a result, the 


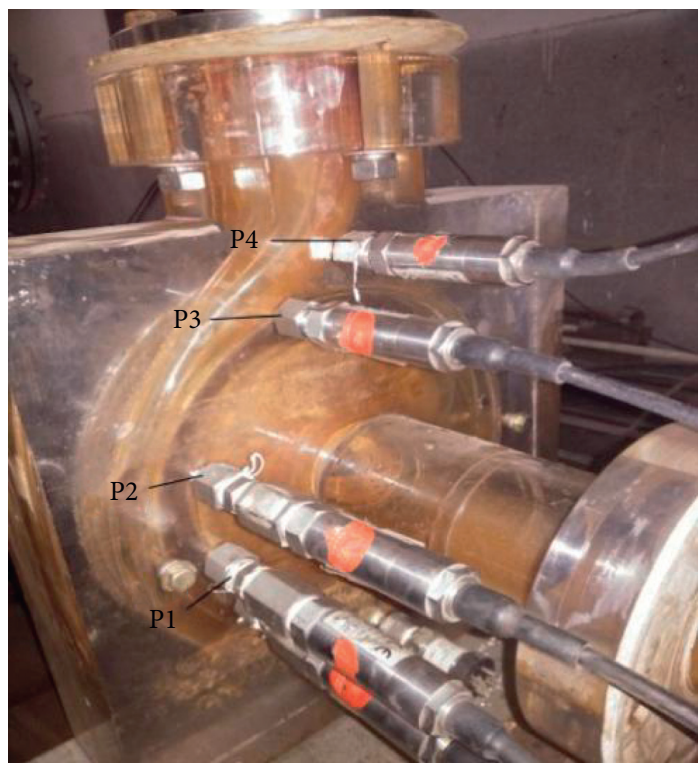

FIgURE 1: Test monitoring points.

TABLE 1: Basic parameters of the guide vane centrifugal pump.

\begin{tabular}{lcc}
\hline & PART parameter number & \\
\hline \multirow{2}{*}{ Impeller } & Outlet diameter $D_{2}(\mathrm{~mm})$ & 233 \\
& Blade outlet width $b_{2}(\mathrm{~mm})$ & 8 \\
& Number of blades $Z_{1}$ & 6 \\
Guide vane & Inlet diameter $D_{3}(\mathrm{~mm})$ & 228 \\
& Outlet diameter $D_{4}(\mathrm{~mm})$ & 283 \\
Volute & Number of blades $Z_{2}$ & 5 \\
\hline
\end{tabular}

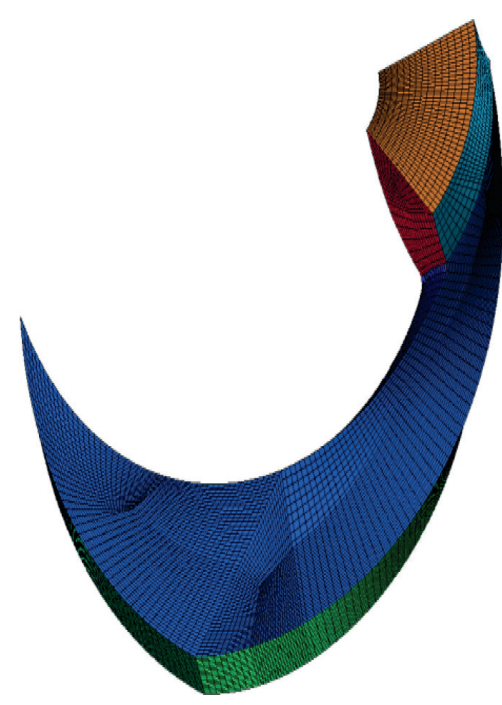

(a)

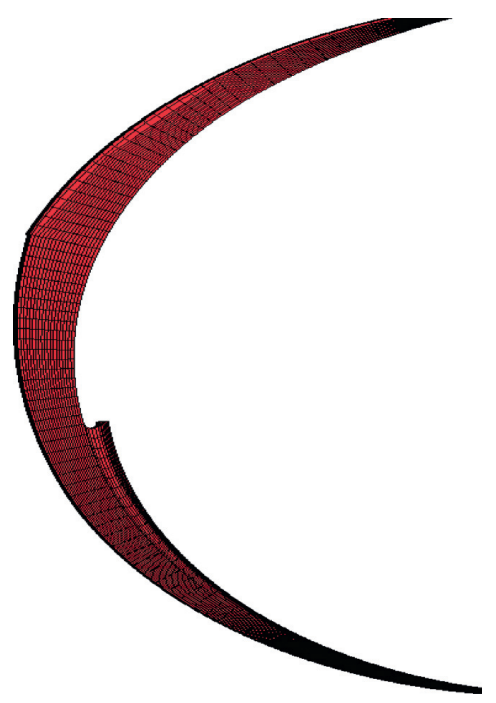

(b)

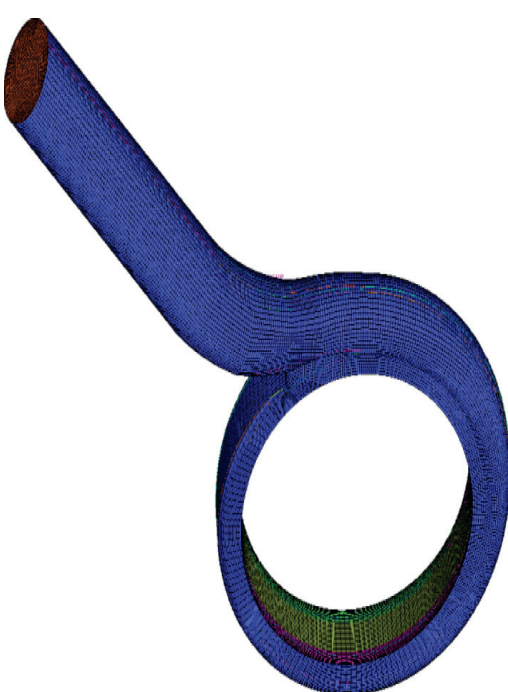

(c)

Figure 2: Three-dimensional meshing with grid: (a) impeller; (b) guide vane; (c) volute. 


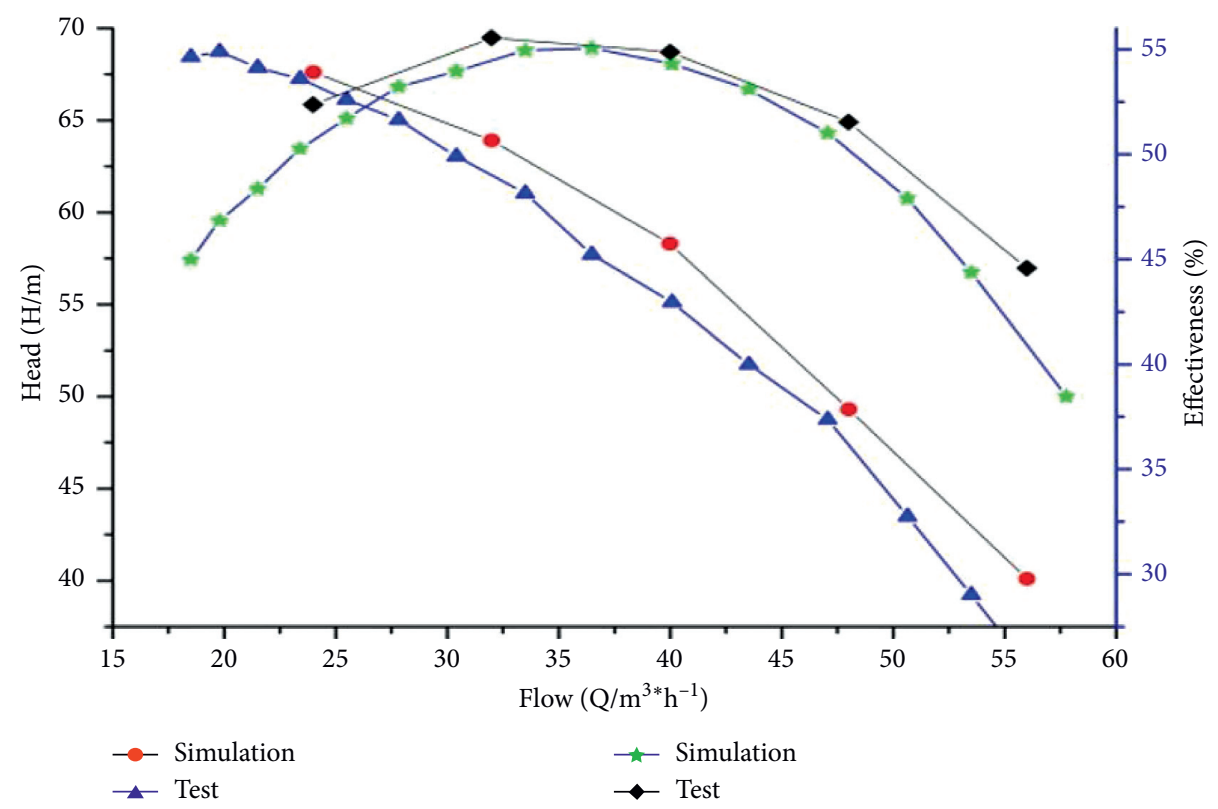

Figure 3: Head efficiency flow curve.
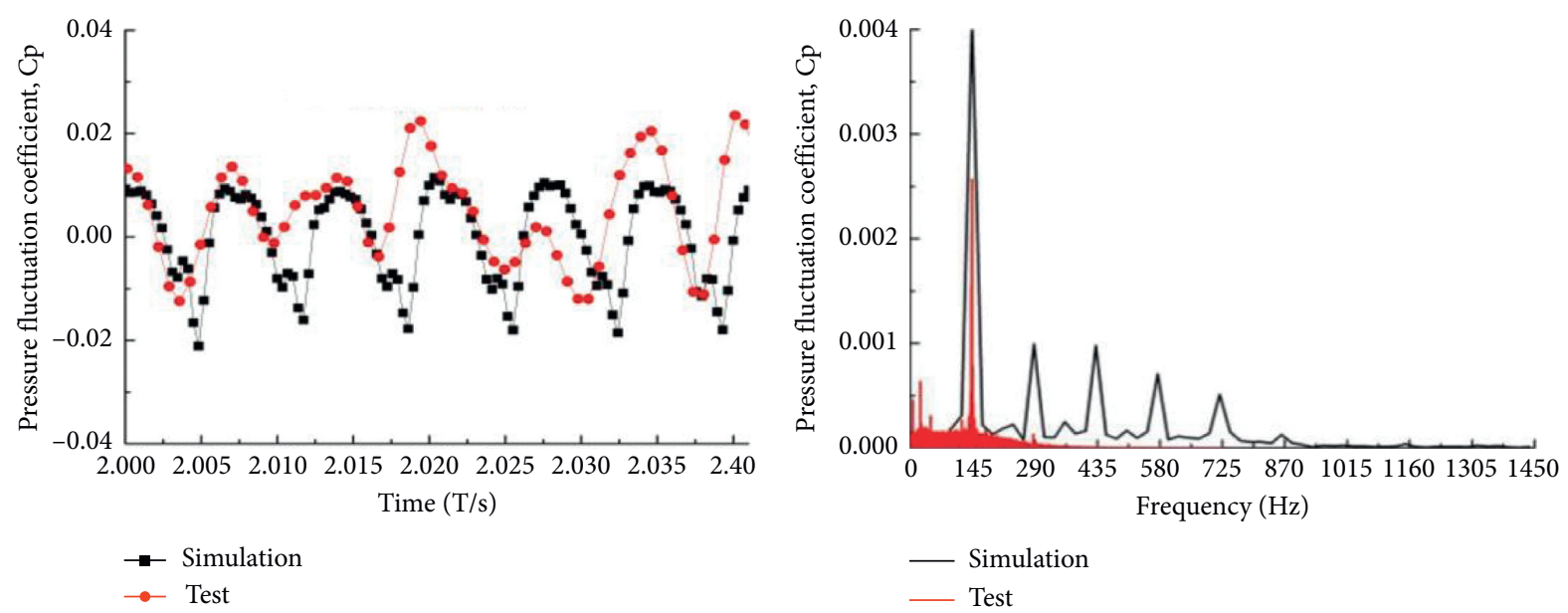

(a)
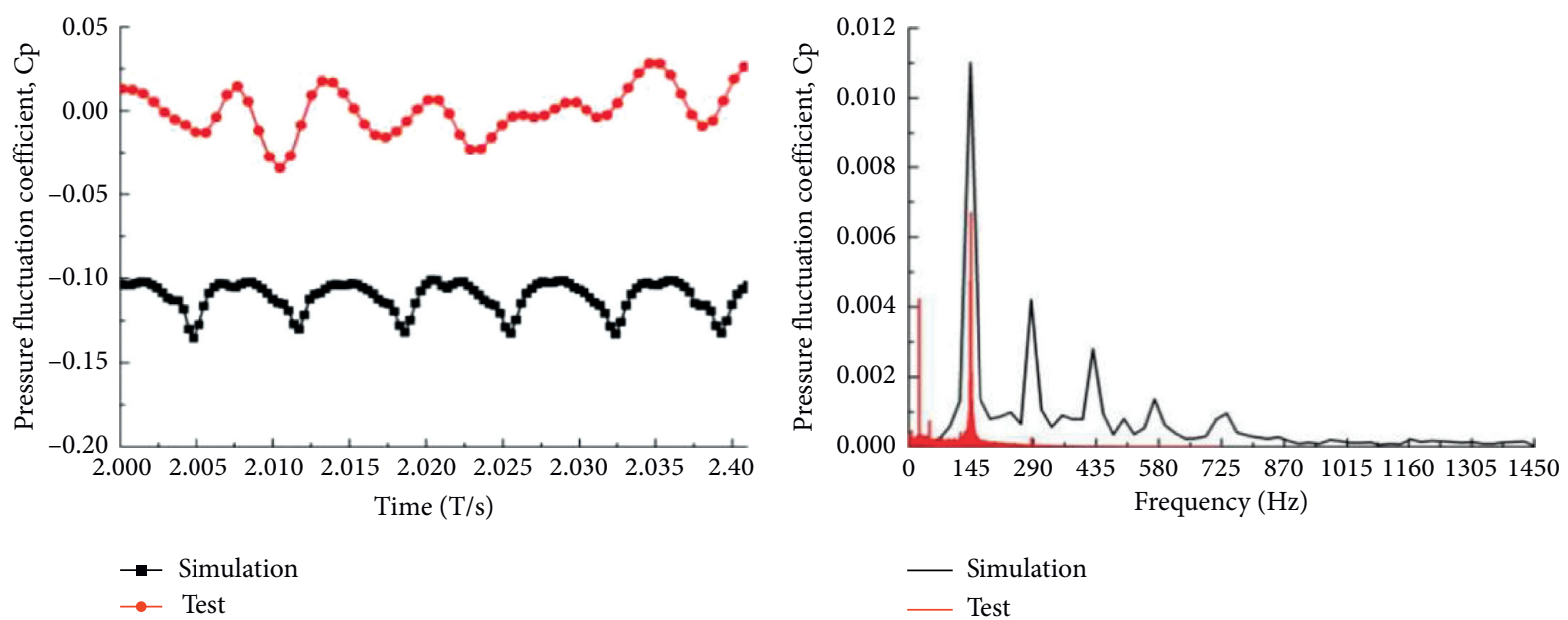

(c)

(d)

Figure 4: Comparison of numerical simulation and test of pressure pulsation at monitoring points $\mathrm{P} 3$ and $\mathrm{P} 4$ under $1.0 \mathrm{Q} / \mathrm{Q}_{\mathrm{d}}$ working condition. (a) Monitoring point P3 pressure pulsation time domain. (b) Monitoring point P3 pressure pulsation frequency domain. (c) Monitoring point P4 pressure pulsation time domain. (d) Monitoring point P4 pressure pulsation frequency domain. 

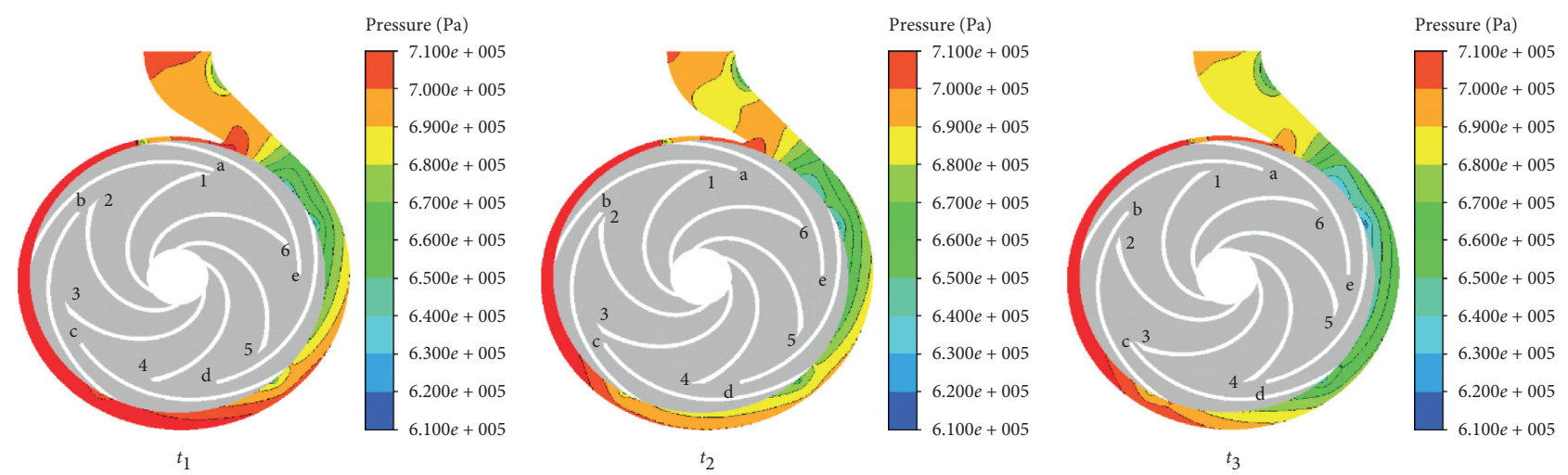

Figure 5: The static pressure distribution of the volute at different times.

simulated value and the actual value are not numerically consistent in Figure 4(c). The flow field of the fluid near the downstream of the compartment is unstable and the pressure fluctuates sharply, as shown in Figure 5.

It can be seen from Figure 5 that the main frequency of the numerical simulation value and test value of the pressure pulsation frequency of the monitoring points $P 3$ and $P 4$ is the leaf frequency. Because the monitoring positions can be accurately arranged in the numerical simulation process, they cannot completely match the positions of the monitoring points in the test. In the numerical simulation process, the gap leakage, disc friction loss, and other factors are not considered, so the amplitude of the pressure pulsation in the numerical simulation is higher than the experimental value at the leaf frequency and harmonic frequency. In summary, the distribution trend of the numerical simulation results is in good agreement with the experiment, which shows that the meshing of the flow components, the boundary conditions, and the selection of the turbulence model in the numerical method are reliable.

\section{Numerical Simulation Results}

3.1. Analysis of Radial Force Acting on the Impeller. The centrifugal pump was designed with uniformly distributed velocity and pressure of the liquid in the pressurized water chamber. The velocity and pressure of the fluid in the impeller channel are axially symmetrical, so the resultant force acting on the impeller is zero, and there is no radial force in theory. However, when the conditions for the interaction and coordination between the pressurized water chamber and the impeller are destroyed or deviate from the design flow rate, there will be a sharp contradiction between them, which will destroy the symmetrical distribution of pressure along the impeller axis, thus generating radial force. Excessive alternating stress acting on the impeller is the main reason for damage to the pump shaft and sealing ring. In the CFX numerical simulation calculation process, the radial force calculation mainly involves pressure and viscous force. The calculation formula is

$$
\begin{aligned}
& F_{x}=\left(\iint_{A_{2}} v_{x} \rho v_{r} d A-\iint_{A_{1}} v_{x} \rho v_{r} d A\right)-\rho \frac{\partial}{\partial t} \int_{v} d Q v_{x}-\iint_{A_{2}} \cos (\theta+\omega t) P\left(r_{2}, \theta\right) d A \\
& F_{y}=\left(\iint_{A_{2}} v_{y} \rho v_{r} d A-\iint_{A_{1}} v_{y} \rho v_{r} d A\right)-\rho \frac{\partial}{\partial t} \int_{v} d Q v_{y}-\iint_{A_{2}} \cos (\theta+\omega t) P\left(r_{2}, \theta\right) d A .
\end{aligned}
$$

Unsteady calculations are performed under multiple flow conditions, and three typical flow conditions of $0.8 \mathrm{Q} / \mathrm{Q}_{\mathrm{d}}, 1.0$ $Q / Q_{d}$, and $1.2 Q / Q_{d}$ are selected for data analysis. After the calculation of each working condition, the stable rotation period is selected for pulsation analysis after convergence, and the time-domain diagram of each point under different flow rates is obtained. Using Origin8.5 drawing software, the pressure-time curve in the time-domain diagram is performed fast. The inner leaf transform is used to obtain the corresponding frequency-domain map, where the abscissa is the frequency and the ordinate is the amplitude of the pressure fluctuation, as shown in Figure 6(a). With reference to the frequency spectrum characteristics of each flow rate, it can be concluded that the pressure fluctuations within $600 \mathrm{~Hz}$ have large amplitudes. Fluctuation amplitudes above $600 \mathrm{~Hz}$ are relatively small, and the contribution to the pressure fluctuations is also small. Therefore, the pressure fluctuations in the pump are mainly affected by the influence of low and medium frequency waves. Analyzing the data obtained by FFT transformation shows that under different flow rates, the main frequency of pressure fluctuations is concentrated at about $70 \mathrm{~Hz}$. As the flow rate increases, the amplitude gradually decreases, indicating that as the flow rate increases, the radial force acting on the impeller gradually decreases. It can be seen from Figure 6(b) that the magnitude and direction of the radial force acting on the impeller changes with the 


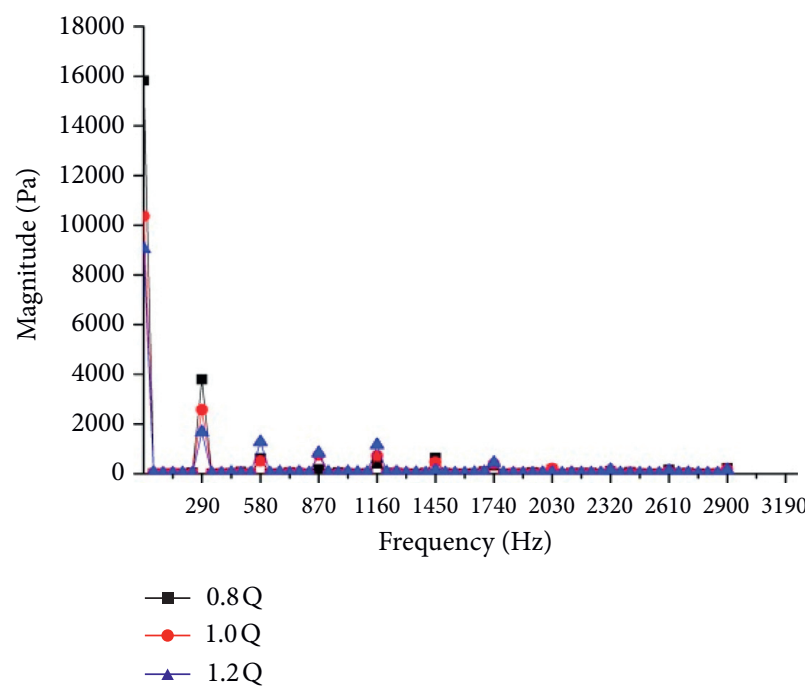

(a)

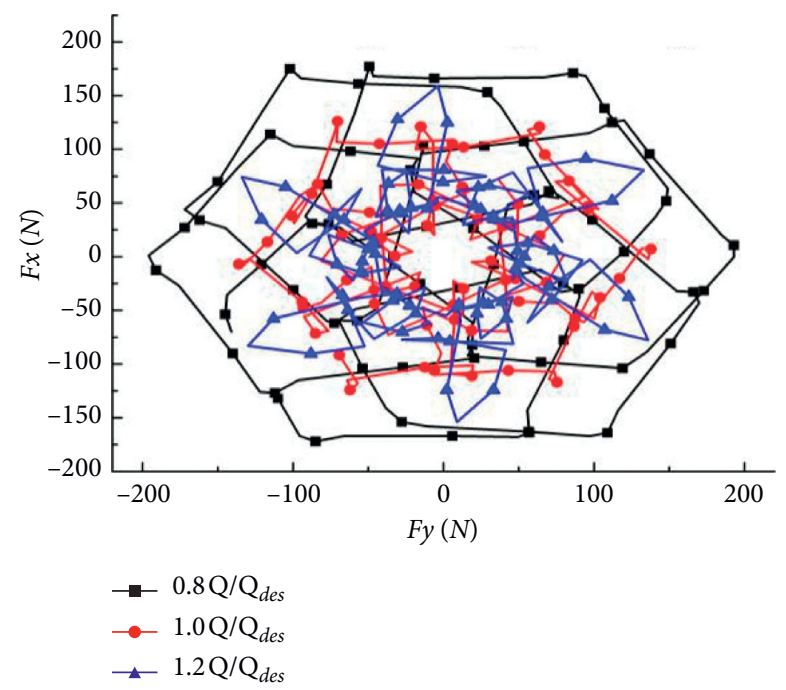

(b)

Figure 6: Frequency domain and vector distribution of radial force acting on the impeller at different flow rates. (a) Fourier transform frequency domain. (b) Radial force vector.

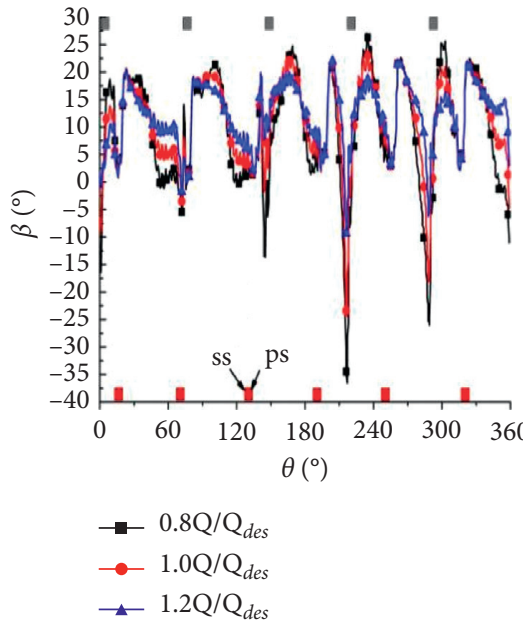

(a)

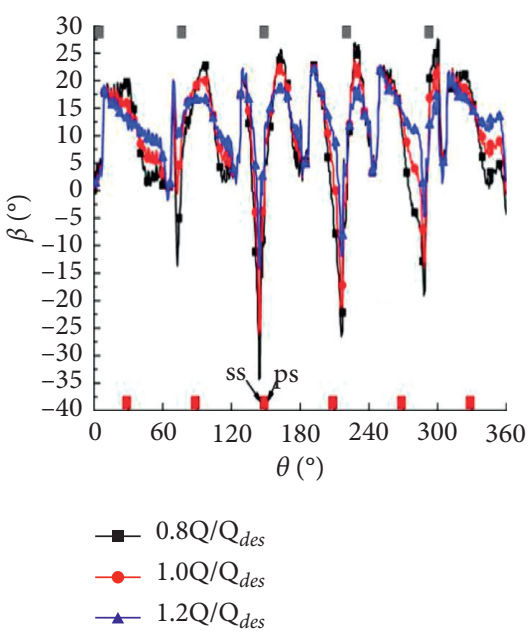

(b)

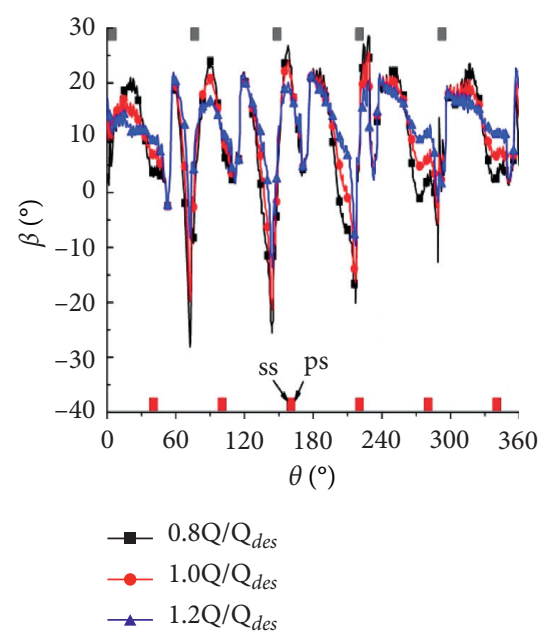

(c)

FIGURe 7: Different flow rates, different moments, the relative liquid flow angle distribution at the outlet of the impeller $Z=0$. (a) $t_{1}$; (b) $t_{2}$; (c) $t_{3}$.

rotation direction of the impeller. The distribution presents a hexagonal or hexagonal shape, which is the same as the number of impeller blades; the absolute speed and relative speed are changing in direction and number. The radial force acting on the impeller changes unsteadily, and its magnitude and direction change all the time.

Figure 7 shows the distribution of the relative liquid flow angle $(\beta)$ at the impeller outlet at different flow rates at different times. It can be seen from the figure that as the flow rate increases, the relative liquid flow angle fluctuation at the impeller outlet gradually decreases, and the distribution is more uniform. The angular symmetry is good, which can further explain that the change in the magnitude and direction of the radial force acting on the impeller is affected by the impeller outlet speed. The magnitude and direction of the force can show better regularity.

At different flow rates, the average pressure is evenly distributed, and the pressure of each flow channel shows good symmetry, but the instantaneous pressure symmetry of each flow channel of the impeller is poor. It can be clearly stated that the pressure distribution at the outlet of the impeller is mainly affected by the rotor-stator interference of the impeller and the guide vane, so that the pressure at the outlet of the impeller changes all the time, and the pressure of each flow channel is asymmetric. The impeller-guide vane rotor-stator interference is the main reason for the radial 


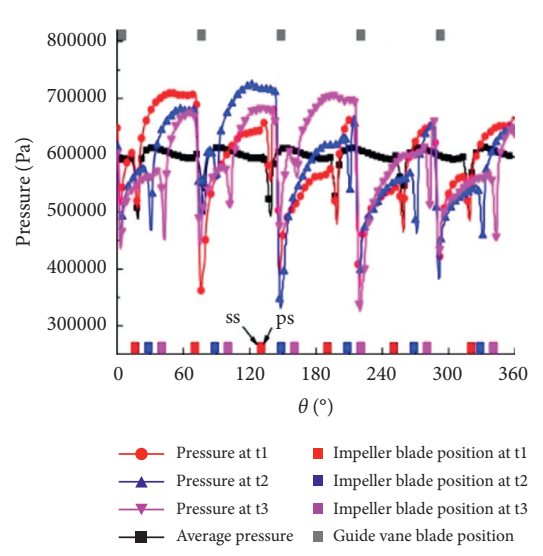

(a)

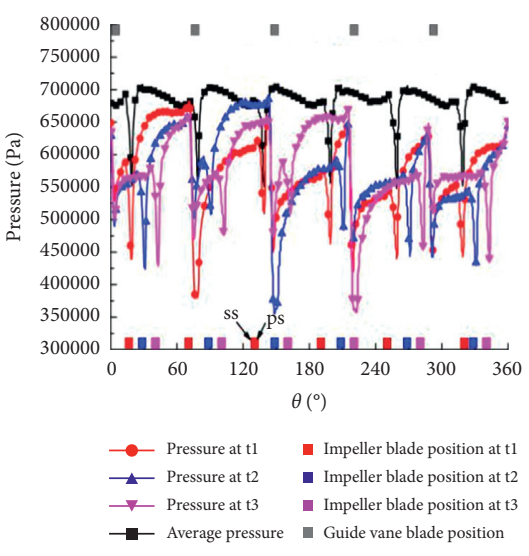

(b)

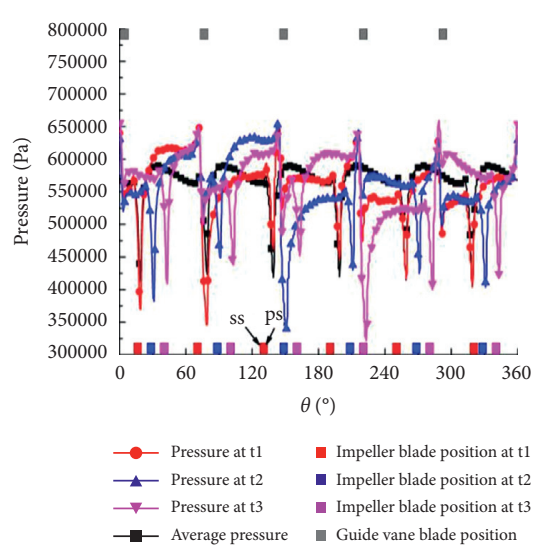

(c)

FIGURE 8: The instantaneous and average pressure distribution of the section along the circumferential direction of the impeller outlet under different flow conditions. (a) $0.8 \mathrm{Q} / \mathrm{Q}_{d}$. (b) $1.0 \mathrm{Q} / \mathrm{Q}_{d}$. (c) $1.2 \mathrm{Q} / \mathrm{Q}_{d}$.

force of the impeller, while the asymmetric geometry of the volute is a secondary factor.

\subsection{Pressure Distribution along the Circumferential Direction} in Impeller Outlet. In order to analyze the pressure distribution along the circumferential direction of the cross section of the impeller outlet under different working conditions, a numerical simulation of the centrifugal pump under multiple working conditions was carried out. Figure 8 shows the instantaneous pressure and average pressure distribution of the impeller outlet section along the circumferential direction under different flow rates and moments. It can be seen from the figure that under different flow conditions, the instantaneous pressure at the impeller outlet increases simultaneously with the flow, and the pressure symmetry distribution of each flow channel of the impeller gradually stabilizes, which shows that the pressure asymmetry in each flow channel of the impeller is the main reason for the radial force of the impeller. As the flow rate increases, the radial force acting on the impeller gradually decreases. Under the same flow conditions and at different times, the instantaneous pressure distribution trends are similar: under the influence of dynamic and static interference, the pressure peak and the trough are, respectively, located on the pressure surface and suction surface of the leading edge of the guide vane. The pressure at the trailing edge of the impeller has a greater impact on the static pressure distribution at the impeller outlet, which is more affected by dynamic and static interference.

At different flow rates, the average pressure is evenly distributed, and the pressure of each flow channel shows good symmetry, but the instantaneous pressure symmetry of each flow channel of the impeller is poor. It can clearly show that the pressure distribution at the outlet of the impeller is mainly affected by the interference of the impeller and the guide vane. Make the impeller outlet pressure change all the time, and the pressure of each flow channel is asymmetric. It shows that the impeller-guide vane rotor-stator interference is the main reason for the radial force of the impeller, and the asymmetric geometry of the volute is a secondary factor.

3.3. Analysis of the Internal Flow Field Characteristics. Pressure pulsation is an important factor that induces centrifugal pump vibration and radial force. Vibration, noise, and other phenomena caused by pressure pulsation will have an important impact on the operation stability of centrifugal pumps and shorten the fatigue life of mechanical parts, seriously destroying the comfort of the working environment. Figure 9 shows the intensity distribution of cross-sectional pressure pulsation in the impeller channel under different flow rates. The pressure pulsation intensity $C_{p}$ is solved by the following equation:

$$
C_{\mathrm{psdv}}=\sqrt{\frac{\sum_{i=1}^{N}\left(C_{P}(i)-\bar{C}_{p}\right)}{N}} .
$$

It can be seen from the figure that at different flow rates, the pulsation intensity distribution in each impeller flow channel is basically the same, showing good periodicity. The pressure pulsation intensity of the pressure surface of the blade is greater than the suction surface of the blade, and the radial force direction is directed from the pressure surface of the blade to the suction surface. The unsteady rotor-stator interference has a greater impact on the pressure surface of the impeller blade. Under $0.8 Q / Q_{\mathrm{d}}$ and 1.0 $Q / Q_{\mathrm{d}}$ flow, due to the influence of the exit wake flow, the maximum pressure pulsation intensity appears in the middle area of the impeller flow channel outlet, where the maximum radial force is generated; compared with other flow conditions, $1.2 \mathrm{Q} / \mathrm{Q}_{\mathrm{d}}$, the pulsation intensity at the working face of the trailing edge of the blade has a maximum value. Pulsation intensity near the working surface of the blade trailing edge gradually increases with the increase of flow, but the pulsation intensity gradient changes more uniformly with the radial force tending to be stable. 


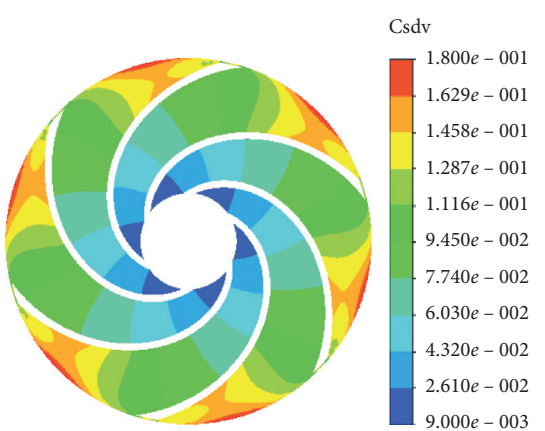

(a)

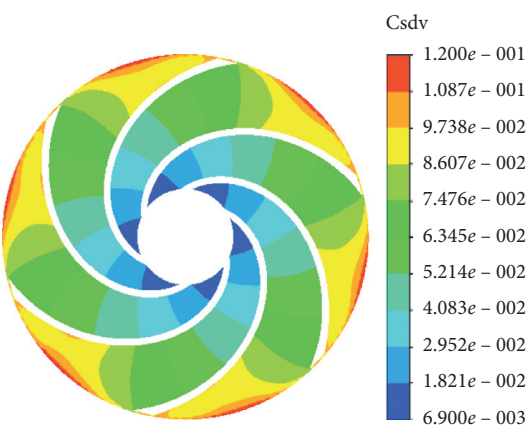

(b)

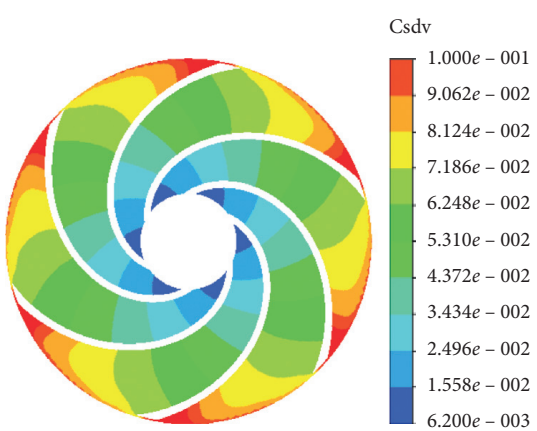

(c)

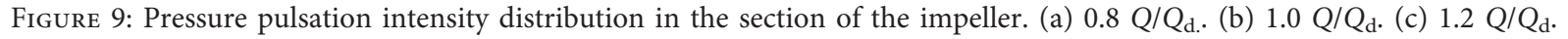

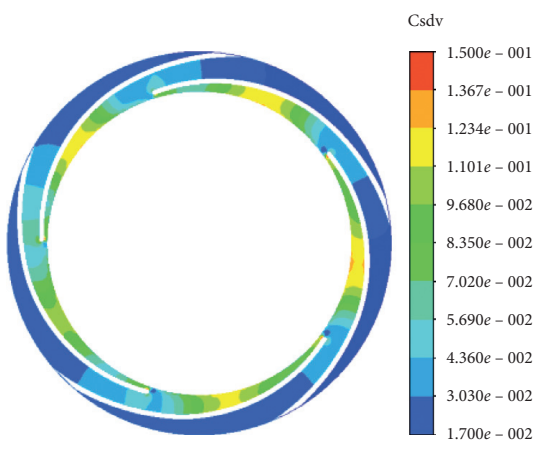

(a)

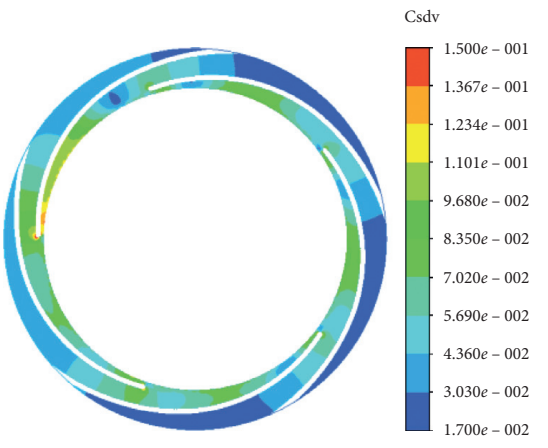

(b)

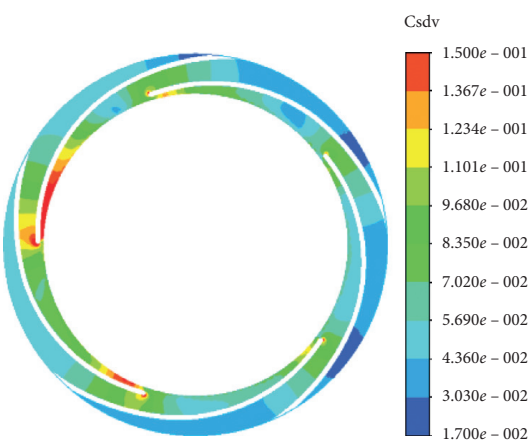

(c)

FIGURE 10: Intensity distribution of cross-sectional pressure fluctuation in the guide vane. (a) $0.8 Q / Q_{d}$. (b) $1.0 \mathrm{Q} / Q_{d}$. (c) $1.2 \mathrm{Q} / Q_{d}$.

Figure 10 shows the intensity distribution of crosssectional pressure pulsation in the guide vane at different flow rates. The guide vane channel can be divided into three areas: spiral section, diffusion section, and transition section. It can be seen from the figure that the intensity of pressure pulsation, that is, the maximum value of radial force, is concentrated on the spiral section of the guide vane or the leading edge of the guide vane under various flow conditions. Since the spiral section mainly functions to collect liquid, it is greatly affected by the impeller wake flow. And the intensity of pressure pulsation increases with the increase of flow rate. Due to the influence of dynamic and static interference, the pressure pulsation intensity of the impeller and the area with the largest radial force is concentrated at the exit of the impeller, close to the suction surface of the blade. At the same time, the maximum pressure pulsation in the leading edge area of the guide vane is affected by the interference of the trailing edge of the impeller.

The intensity of pressure pulsation gradually decreases along the guide vane flow path. The pulsation intensity distribution at the spiral section of the guide vane is extremely complicated: (1) unsteady dynamic and static interference gradually weakens along the radius, so the pulsation strength and radial force gradually decrease along the radius; (2) under the influence of the leading edge of the guide vane, the pulsation intensity in the direction of rotation of the impeller first rises and then falls, especially for the pulsation intensity from the leading edge of the guide vane.

\section{Conclusions}

This study revealed the internal unsteady flow state of the guide vane centrifugal pump. Under the standard SST k- $\omega$ turbulent flow model, the centrifugal pump is numerically simulated in an unsteady state. By analyzing the characteristics of the internal flow field of the centrifugal pump, the resultant force of the radial force of the centrifugal pump guide vane and impeller under different flow rates is obtained:

(1) As the flow rate gradually increases, the frequencydomain amplitude of the impeller gradually decreases with the radial force; the magnitude and direction of the radial force acting on the impeller changes with the direction of rotation of the impeller, and the distribution presents a hexagonal shape or hexagonal.

(2) For different flow rates, the instantaneous pressure at the impeller outlet increases with the flow rate. The pressure asymmetry in each channel of the impeller is the main reason for the radial force of the impeller; with the same flow rate, the instantaneous pressure distribution trend is similar at different times; with 
different flow rates, the pressure distribution at the impeller outlet is mainly affected by the impellerguide vane dynamic and static interference. As a result, the outlet pressure of the impeller changes constantly. The pressure of each flow channel is asymmetrical, which explains the main reason for the radial force of the impeller when the impeller and the guide vane interfere with each other.

(3) Due to the influence of dynamic and static interference, the pressure pulsation intensity in the impeller and the area with the largest radial force is concentrated at the impeller outlet, near the suction surface of the blade. Affected by the trailing edge of the impeller and the leading edge of the guide vane, the guide vane inlet area presents the maximum pressure pulsation. At different flow rates, the pulsation intensity distribution in each impeller channel is basically the same, showing good periodicity.

\section{Data Availability}

The data used to support the findings of this study are included within the article.

\section{Conflicts of Interest}

The authors declare that they have no conflicts of interest.

\section{Acknowledgments}

The present study was financially supported by Natural Science Basic Research Plan in Shaanxi Province of China (2020JM-645).

\section{References}

[1] S. Weidong, L. Zhang, B. Chen, T. Jiang, and H. Zhang, "Influence of centrifugal pump clearance on pressure pulsation and radial force," Journal of Drainage and Irrigation Machinery Engineering, vol. 30, no. 3, pp. 260-264, 2012.

[2] S. Fu, Y. Zheng, K. Kan et al., "Numerical simulation and experimental study of transient characteristics in an axial flow pump during start-up," Renewable Energy, vol. 146, pp. 1879-1887, 2020.

[3] L. Shi, W. Zhang, H. Jiao et al., "Numerical simulation and experimental study on the comparison of the hydraulic characteristics of an axial-flow pump and a full tubular pump," Renewable Energy, vol. 153, pp. 1455-1464, 2020.

[4] L. Bai, L. Zhou, X. Jiang, Q. Pang, and D. Ye, "Vibration in a multistage centrifugal pump under varied conditions," Shock and Vibration, vol. 2019, Article ID 2057031, 9 pages, 2019.

[5] H. Yan, X. Su, H. Zhang et al., "Design approach and hydrodynamic characteristics of a novel bionic airfoil," Ocean Engineering, vol. 216, Article ID 108076, 2020.

[6] Y. Yang, L. Zhou, W. Shi, Z. He, Y. Han, and Y. Xiao, "Interstage difference of pressure pulsation in a three-stage electrical submersible pump," Journal of Petroleum Science and Engineering, vol. 196, Article ID 107653, 2020.

[7] G. Peng, X. Huang, L. Zhou, G. Zhou, and H. Zhou, "Solidliquid two-phase flow and wear analysis in a large-scale centrifugal slurry pump," Engineering Failure Analysis, vol. 114, Article ID 104602, 2020.
[8] S. Tang, S. Yuan, and Y. Zhu, "Convolutional neural network in intelligent fault diagnosis toward rotatory machinery," IEEE Access, vol. 8, no. 1, pp. 86510-86519, 2020.

[9] S. Tang, S. Yuan, and Y. Zhu, "Deep learning-based intelligent fault diagnosis methods toward rotating machinery," IEEE Access, vol. 8, no. 1, pp. 9335-9346, 2020.

[10] M. Yang and S. Xin, Wang Fujun-Pressure Pulsation Characteristics Of Double Volute Pump And Numerical Simulation Of Impeller Radial Force, School of Water Conservancy and Civil Engineering, China Agricultural University, Shanghai KSB Pump Co., Ltd., Shanghai, China.

[11] H. Stel, G. D. L. Amaral, C. O. R. Negrao et al., "Numerical analysis of the fluid flow in the first stage of a two-stage centrifugal pump with a vaned diffuser[J]," Journal of Fluids Engineering, vol. 135, no. 7, Article ID 071104, 2013.

[12] W. Segala, H. Stel, V. Hungria et al., "Numerical simulation of the flow in a centrifugal pump with a vaned diffuser," in Proceedings of the ASME-JSME-KSME 2011 Joint Fluids Engineering Conference, pp. 1791-1800, American Society of Mechanical Engineers (ASME), Hamamatsu, Japan, July 2011.

[13] S. Guo and Y. Maruta, "Experimental investigations on pressure fluctuations and vibration of the impeller in a centrifugal pump with vaned diffusers," JSME International Journal Series B, vol. 48, no. 1, pp. 136-143, 2005.

[14] S. OliverJ. Woisetschläger et al., "Laser-Doppler-velocimetry measurements in a one and a half stage transonic test turbine with different angular stator-stator positions," Experiments in Fluids, vol. 43, no. 2-3, pp. 385-393, 2007.

[15] H. JiaK. Vogeler et al., "Effect of clocking on unsteady rotor blade loading in a low-speed axial compressor at design and off-design operating conditions," Proceedings of the Institution of Mechanical Engineers, Part G: Journal of Aerospace Engineering, vol. 222, no. 6, pp. 895-906, 2008.

[16] X. G. U. Chunwei, "Investigation on clocking effect of 1.5stage transonic compressor," Journal of Aerospace Power, vol. 25, no. 4, pp. 891-896, 2010.

[17] Q. Sun, Research on the Influence of Centrifugal Pump Blade Profile on Pump performance, Lanzhou University of Technology, Lanzhou, China, 2011.

[18] C. Wang, "Obtain the continuous falling characteristic curve and improve the efficiency of the centrifugal pump," Pump Technology, no. 2, pp. 38-39, 1991.

[19] I. Chalghoum, S. Elaoud, H. Kanfoudi, and M. Akrout, "The effects of the rotor-stator interaction on unsteady pressure pulsation and radial force in a centrifugal pump," Journal of Hydrodynamics, vol. 30, no. 4, pp. 672-681, 2018.

[20] H. Yue and L. Tan, "Symmetrical and unsymmetrical tip clearances on cavitation performance and radial force of a mixed flow pump as turbine at pump mode," Renewable Energy, vol. 127, pp. 368-376, 2018.

[21] J. F. Guelich and R. Egger, Part Load Flow and Hydraulic Stability of Centrifugal Pumps, Epri, Washington, DC, USA, 1992.

[22] K. Fischer, Investigation of Flow in a Centrifugal Pump, National Advisory Committee for Aeronautics Technical Memorandum No.1089, Washington, DC, USA, 1946.

[23] N. Krause, K. Zahringer, and E. Pap, "Time-resolved particle imaging velocimetry for the investigation of rotating stall in a radial pump," Experiments in Fluids, vol. 39, no. 2, pp. 192-201, 2005.

[24] K. A. Kaupert and T. Staubli, "The unsteady pressure field in a high specific speed centrifugal pump impeller-Part II: transient hysteresis in the characteristic," Journal of Fluids Engineering, vol. 121, no. 3, 2007. 
[25] N. Agrawal, K. Agrawal, and S. Mhaske, "Experimental investigation of rotor-stator interaction in a centrifugal pump with several vaned diffusers," Journal of Turbomachinery, vol. 112, no. 1, pp. 98-108, 1990.

[26] T. Kreuz-Ihli, D. Filsinger, A. Schulz et al., "Numerical and experimental study of unsteady flow field and vibration in radial inflow turbines[J]," Journal of Turbomachinery, vol. 122, no. 2, Article ID V001T003A053, 2000.

[27] F. A. Muggli, K. Eisele, M. V. Casey, J. Gulich, and A. Schachenmann, "Flow analysis in a pump diffuser-Part 2: validation and limitations of CFD for diffuser flows," Journal of Fluids Engineering, vol. 119, no. 4, pp. 978-984, 1997.

[28] J. Yang, G. Pavesi, S. Yuan et al., "Experimental characterization of a pump-turbine in pump mode at hump instability region," Journal of Fluids Engineering, vol. 137, no. 5, 2015. 